\title{
Field Results on Developed Three-Phase Four-Wire Shunt Active Power Filters
}

\author{
J. G. Pinto, Pedro Neves, D. Gonçalves, João L. Afonso \\ Industrial Electronics Department \\ University of Minho \\ Guimarães, Portugal \\ Email: \{gpinto|pneves|dgoncalves|jla\}@dei.uminho.pt
}

\begin{abstract}
This paper presents three-phase four-wire Shunt Active Power Filters with ability to compensate current harmonics, power factor, and current unbalance. The power stage of the Active Power Filters is based on a two-level four-leg inverter. The switching technique is based on an optimized periodic sampling strategy, and the digital controller uses the Theory of Instantaneous Reactive Power (p-q Theory) expanded for threephase four-wire systems. The presented Active Power Filters were successfully demonstrated in four different facilities. The presented experimental results show the performance of the Active Power Filters in operation with very different load profiles.
\end{abstract}

\section{INTRODUCTION}

The increasing use of rectifiers, thyristor power converters, arc furnaces, switching power supplies and other non linear loads is known to cause serious problems in electric power systems [1]. These problems can be partially solved with the use of passive filters, however, this kind of filtering cannot adapt to variations of the loads, and they also can produce undesired resonances [2]. One solution to avoid these problems is the Shunt Active Power Filter. These devices work as current sources, connected in parallel with the electric grid, and they are capable of providing the harmonics and the reactive power required by the loads [3]. Three-phase four-wire Shunt Active Power Filters are also capable of compensating unbalance and zero sequence currents, minimizing the neutral current [4]. In this way, the mains only supply the fundamental, balanced currents with a unitary power factor, avoiding voltage distortion and reducing power losses in the transmission lines.

This paper appears in sequence of the work developed at the Energy and Power Electronics Laboratory of the University of Minho (Portugal), which had as main objective to develop prototypes of Shunt Active Power Filters to be used to demonstrate the applicability and advantages of this kind of devices in real facilities. With the help of low cost Power Quality Monitors (also developed at University of Minho [5]), various electrical power plants were monitorized. Based in the data collected with the monitorizations, four installations were chosen to exhibit the operation of the Active Power Filters. To show the major advantages and the ability of Active Power Filters to compensate any type of load disturbance, the selected facilities have very different characteristics. The first facility selected is in a large textile industry, and consists in a electrical switchboard that feeds a bulky machine for cloth whitening, comprising many variable speed drivers. The second chosen installation is the switchboard of a computational center. The third place consists in the electrical switchboard of a clinical analyses laboratory, in a hospital. The fourth site is the main electrical switchboard of a medical drugs distribution warehouse.

A summary involving the major topics of this paper is described as follows. The developed Active Power Filters configuration, and a set of equations describing the control theory based on the Instantaneous Reactive Power theory for three-phase four-wire systems are presented in Section II. Aspects related to the construction of the Active Power Filter prototypes are detailed in Section III. In Section IV experimental results are presented and analyzed. Finally, conclusions and suggestions for further works are presented in Section V.

\section{ACTIVE POWER Filter CONFIGURATION}

The power stage of the developed Shunt Active Power Filters is composed by a standard two-level, four-leg Voltage Source Inverter (VSI) that uses eight IGBTs and an electrolytic capacitor in the DC side. Fig. 1 shows the block diagram of the three-phase four-wire Shunt Active Power Filter. The inductors $(L)$ are used to connect the inverter to the electric grid. The controller requires the three phase to neutral system voltages $\left(v_{a}, v_{b}, v_{c}\right)$, the DC link voltage $\left(V_{d c}\right)$, the four load currents $\left(i_{L a}, i_{L b}, i_{L c}, i_{L n}\right)$, and the four inverter currents $\left(i_{f a}, i_{f b}, i_{f c}, i_{f n}\right)$. When the Shunt Active Power Filter is connected, the source currents $\left(i_{S a}, i_{S b}, i_{S c}\right)$ become balanced and sinusoidal, and the neutral source current $\left(i_{S n}\right)$ becomes practically zero.

The control strategy is based on the Theory of the Instantaneous Reactive Power (p-q theory) introduced by Akagi et al. [6] and expanded to three-phase four-wire systems by Aredes et al. [7]. It applies an algebraic transformation (Clarke transform) of the three-phase system voltages and load currents in the $a-b-c$ coordinates to the $\alpha-\beta-0$ coordinates.

After the transformation, the $\mathrm{p}-\mathrm{q}$ theory components are achieved by the expressions (1-3), where $p$ is the instantaneous real power, $q$ is the instantaneous imaginary power (by definition) and $p_{0}$ is the instantaneous zerosequence power. 


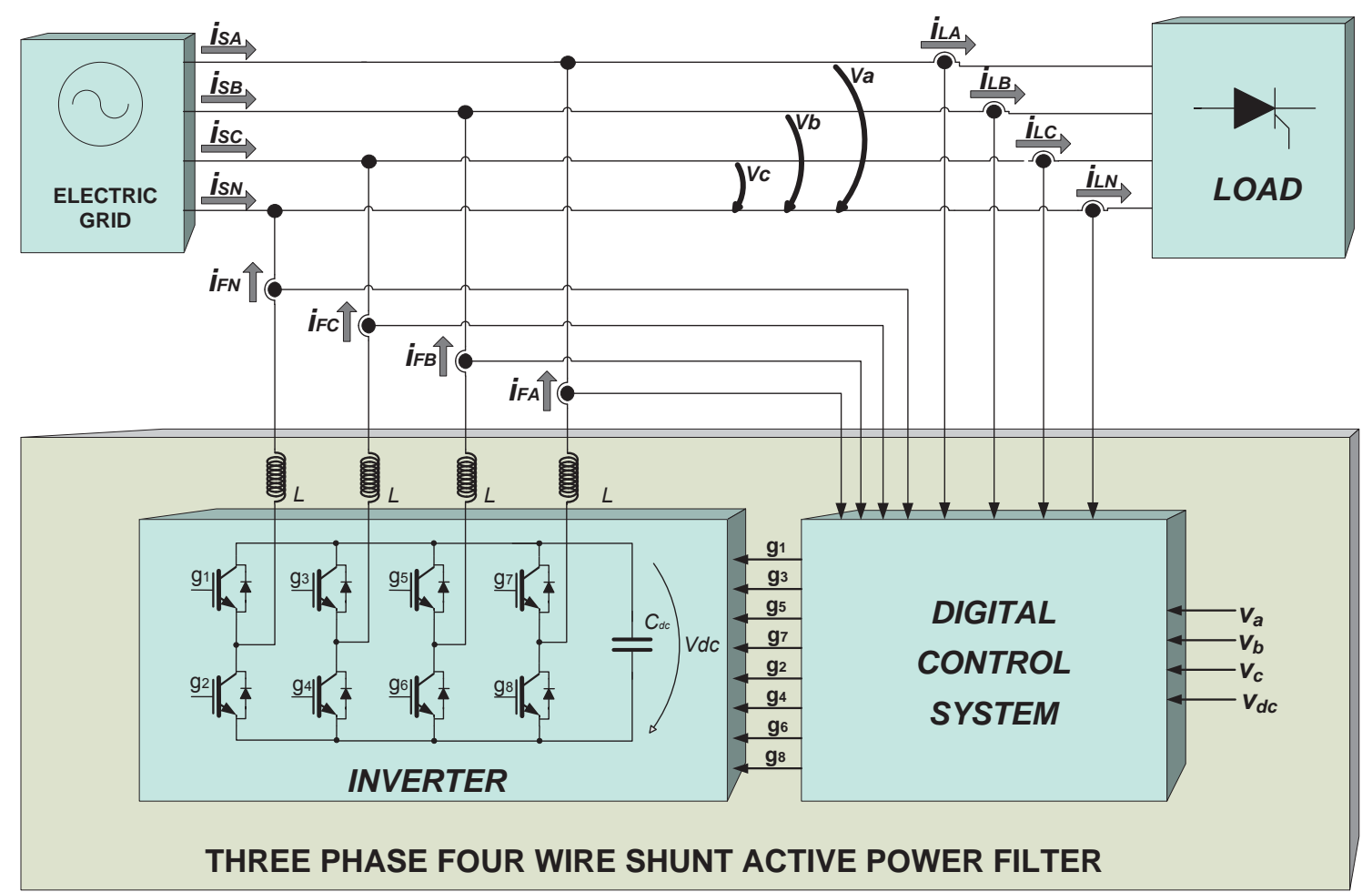

Fig. 1 Block diagram of the three-phase four-wire Shunt Active Power Filter

$$
\begin{aligned}
& p=v_{\alpha} \cdot i_{\alpha}+v_{\beta} \cdot i_{\beta} \\
& q=v_{\beta} \cdot i_{\alpha}-v_{\alpha} \cdot i_{\beta} \\
& p_{0}=v_{0} \cdot i_{0}
\end{aligned}
$$

Each one of the instantaneous power components can be separated into an average value and an oscillating value. The physical meaning for each of the instantaneous power components is:

- $\bar{p}$ - Average value of the instantaneous real power, $p$. Corresponds to the energy per time unit transferred from the source to the load, in a balanced way, through the 3 phases;

- $\widetilde{p}$ - Oscillating value of the instantaneous real power, $p$. It is the energy per time unity that is exchanged between the power source and the load, through the 3 phases;

- $q$ - Instantaneous imaginary power, $q$. Corresponds to the power that is exchanged between the phases of the load. This component does not imply any transference or exchange of energy between the power supply and the load, but is responsible for the existence of undesirable currents in the electrical feeders;

- $\bar{p}_{0}$ - Mean value of the instantaneous zero-sequence power, $p_{0}$. It corresponds to the energy per time unity that is transferred from the power source to the load through the zero-sequence components of voltage and current;

- $\widetilde{p}_{0}$ - Oscillating value of the instantaneous zero-sequence power, $p_{0}$. It means the energy per time unity that is exchanged between the power source and the load through the zero-sequence components of voltage and current.
The capacitor voltage can be kept constant by a control algorithm that exchanges the required energy with the electric grid. To accomplish this task, in addition to the standard power components, one new component, $p_{\text {reg }}$, is also used to regulate the capacitor voltage. The power components that will be injected by the shunt Active Filter, $p_{x}$ and $q_{x}$, include the undesired power quality effects to be compensated: harmonics currents, current unbalance and reactive power.

$$
\begin{aligned}
& p_{x}=p_{\text {reg }}+\tilde{p} \\
& q_{x}=q
\end{aligned}
$$

Finally, it is possible to calculate the reference currents, in the $\alpha-\beta-0$ coordinates, by applying the expressions (6) and (7). The reference currents are then translated to the $a-b-c$ coordinates through the inverse Clarke transform.

$$
\begin{aligned}
& {\left[\begin{array}{l}
i_{c \alpha} \\
i_{c \beta}
\end{array}\right]=\frac{1}{v_{\alpha}^{2}+v_{\beta}^{2}} \cdot\left[\begin{array}{cc}
v_{\alpha} & v_{\beta} \\
-v_{\beta} & v_{\alpha}
\end{array}\right] \cdot\left[\begin{array}{l}
p_{x} \\
q_{x}
\end{array}\right]} \\
& i_{c 0}=i_{0}=\frac{1}{\sqrt{3}} \cdot\left(i_{a}+i_{b}+i_{c}\right)
\end{aligned}
$$

The modulation technique used to drive the IGBTs is the Periodic Sampling, which is a very robust technique that establishes an upper frequency limit, but does not work with a fixed switching frequency [8]. 


$$
\text { III. }
$$

The developed work began with computational simulations on control strategies, switching techniques and hardware topologies. The first results were obtained using the simulation tool PSCA (from The anitoba C esearch Centre Inc.) to validate the proposed control algorithm. From previous experience, it is possible to verify that if the simulation model is accurately modeled and the details of hardware implementation are taken into consideration, the simulation results are very similar to the ones measured in the developed prototype [10]. A second phase consisted in implementing a laboratory prototype of the described Shunt Active Power Filter, and testing the proposed control theory and switching technique. In Fig. it is possible to see the implemented laboratory prototype. It uses a Texas Instruments SP, and the control system was implemented using only fixed point calculations in order to enhance performance in terms of execution time. all effect sensors were used to measure the voltages and currents. The inverter stage was implemented using $4 \mathrm{~S}$ I $\quad \mathrm{O}$ IGBT modules (one for each leg of the inverter).

Two of the most important aspects when an equipment prototype is installed in field environment are security and reliability. The security of the human operators, the security of the industry plant, and the integrity of the equipment are factors that must be evaluated carefully. Therefore, it is very important to protect the Active Power Filter against phenomena that usually do not exist in a laboratory environment, but that may occur in industry. To accomplish these estrangements, the laboratory prototype was designed to be assembled in an electric board (Fig. 3). To prevent that anomalous operations can damage the Active Power Filter components or other equipment connected to the electrical grid, various protections schemes were implemented. A supervisory and protection system was developed to permanently monitorize the Active Power Filter operation parameters, and to disconnect the device if any anomalous

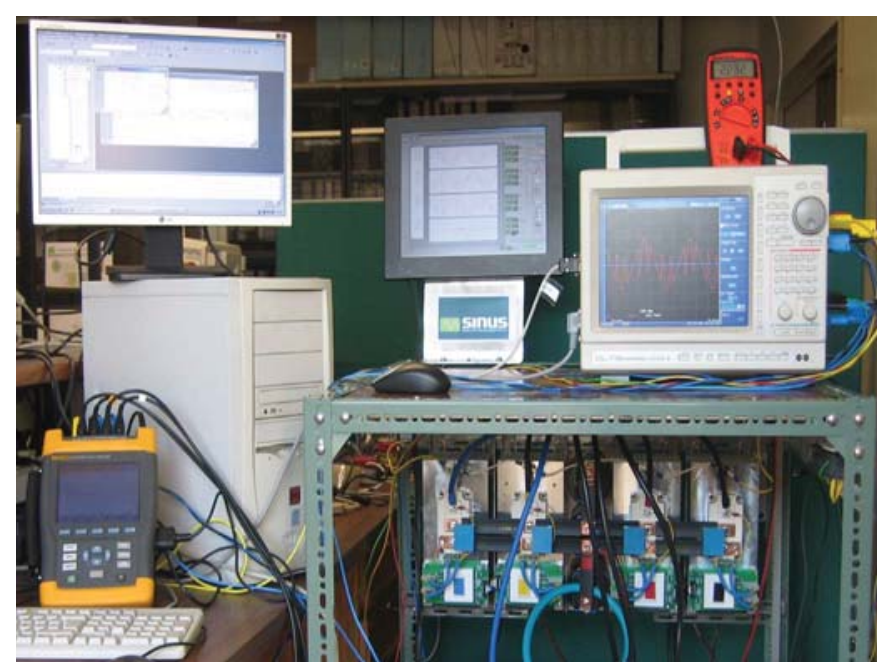

Fig. 2 aboratory prototype of the Shunt Active Power Filter

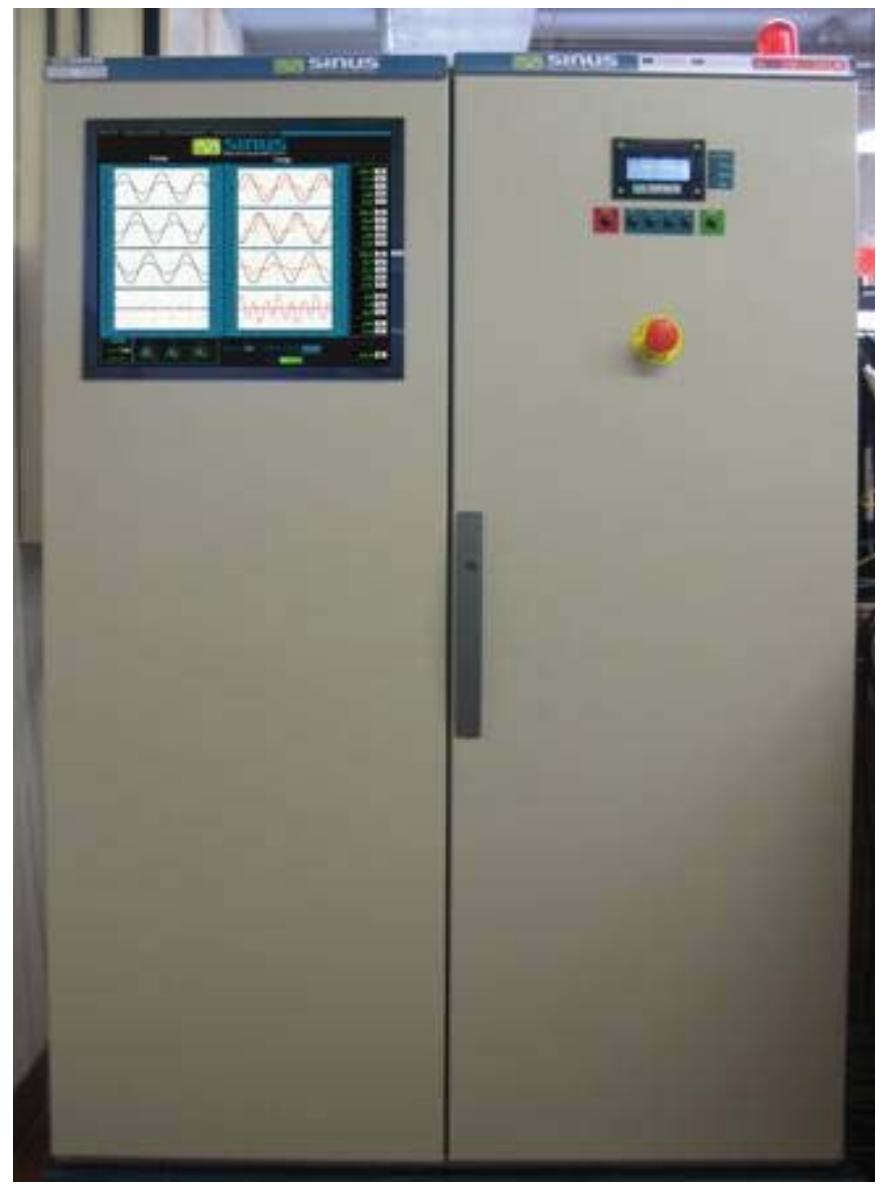

Fig. 3 One of the four final prototypes of Shunt Active Power Filter

values are detected. Some of the protections implemented have two levels of actuation, in a first level the problem can be detected through software algorithms, and the Active Power Filter is softly turned off if the problem persists. ore extreme malfunctions will activate implemented hardware protections that instantaneously disconnect the Active Power Filter from the electric grid and also discharge the $\mathrm{C}$ side capacitors. The supervisory and protection system also has the responsibility to correctly operate the Active Power Filter. It is responsible for the soft connection of the Active Power Filter to the electric grid, performing the pre-charge of the $\mathrm{C}$ capacitors. Some of the implemented protections are: protection against abnormal system voltages (protections for different values of transitory and $\mathrm{S}$ values are implemented) protection against overcurrents produced by the Active Power Filter (the maximum compensation currents are limited by software, but several malfunctions can origin a current higher than the inverter limit, triggering the protection). Protections against high temperature are also implemented through temperature sensors assembled in various representative points. Temperature sensors also allow the $\mathrm{O}$ OFF control of the electric board ventilation fans, which are responsible for cooling the heatsinks of the IGBTs modules, and the inductors (that connect the inverter to the electric grid). 


$$
\text { I . }
$$$$
\mathrm{P}
$$

TA

S TS

The developed prototypes are demonstrated in operation in four different installations. The target installations were previously monitorized and simulation models of each installation were developed using the PSCA simulation tool. The simulation models were used to foresee the Active Power Filter behavior and to help sizing the hardware components and the protection limits. According to these previous studies, four Shunt Active Power Filters were constructed within three different compensation ranges. Two $20 \mathrm{k}$ A prototypes to be used in the computation center and in the hospital, a $35 \mathrm{k}$ A prototype to be used in the textile industry installation, and a $55 \mathrm{k}$ A prototype to be applied in the medical drugs distribution warehouse. The experimental results achieved in the four demonstration installations are presented in the next topics:

exie $r$

The first place selected to the demonstration of the Active Power Filters consists in an electrical switchboard that feeds a

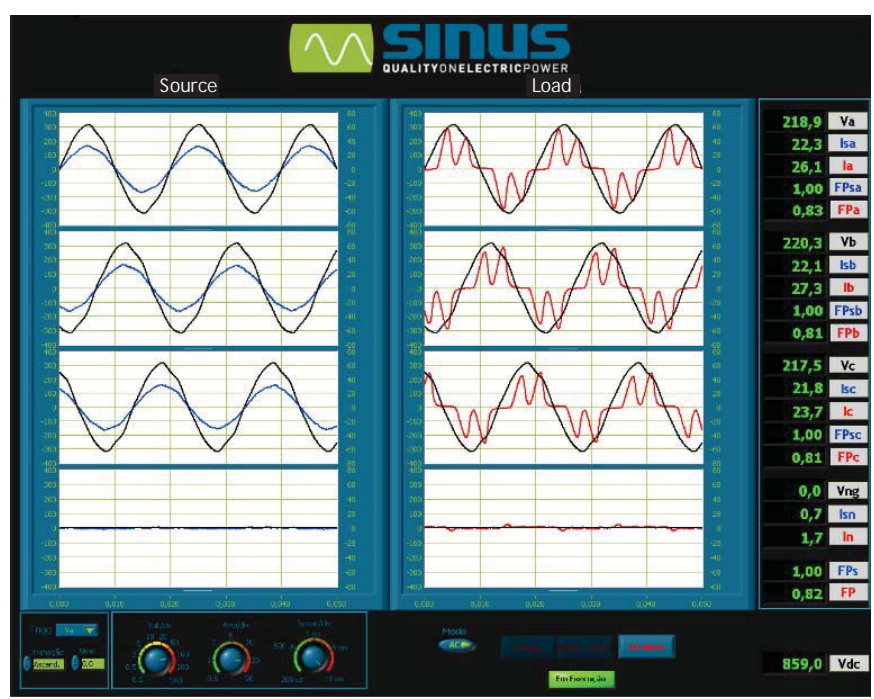

Fig. 4 System voltages and currents waveforms at oad and Source sides, registered in installation 1 (Textile Industry).

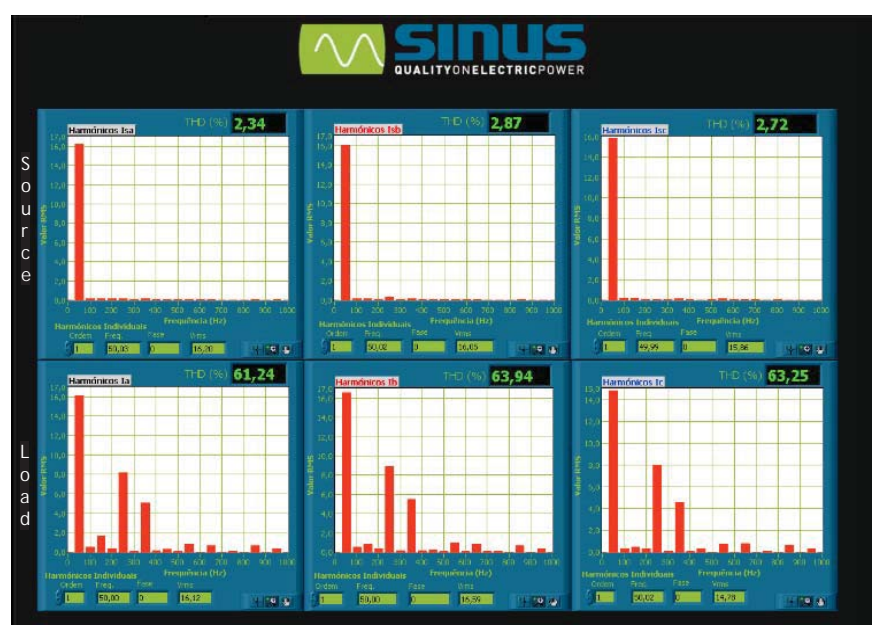

Fig. 5 Current harmonics and $\mathrm{T}$ at oad and Source sides, registered in installation 1 (Textile Industry). cloth whitening machine, in a large textile industry. ere, the load is composed by eight variable speed drives with different power rates.

The load currents present a high $\mathrm{T} \quad$ (greater then 60 in all the three phases), the fifth and seventh harmonics are the highest one but other harmonics are also present (see Fig. 5 oad). The neutral current is nearly zero. Fig. 4 shows the voltage and current waveforms and $\mathrm{S}$ values measured with the Active Power Filter connected to the grid. In these figure it is possible to see that at load side (red) the three phase currents are distorted and at source side (blue) the three phase currents becomes almost sinusoidal, and in phase with the system voltages (the total power factor increases from 0.82 to 1 ). According to the measures presented in Fig. 5, the source current $\mathrm{T}$ of all the three phases decreases to values smaller than 3

$$
p \text { ai a e er }
$$

The second demonstration installation consists in the electrical switchboard of a computational center, at

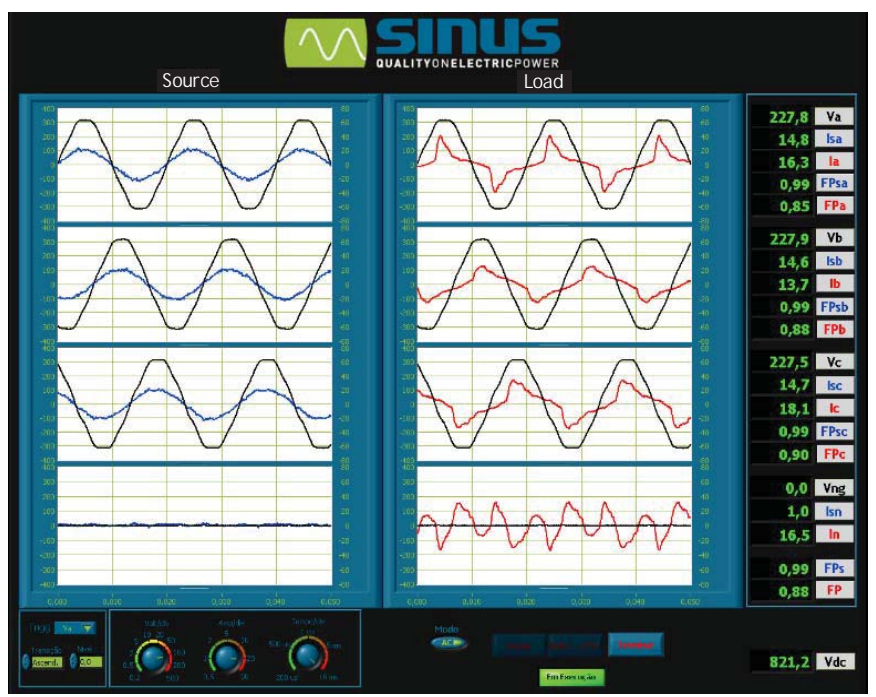

Fig. 6 System voltages and currents waveforms at oad and Source sides, registered in installation 2 (Computational Center).

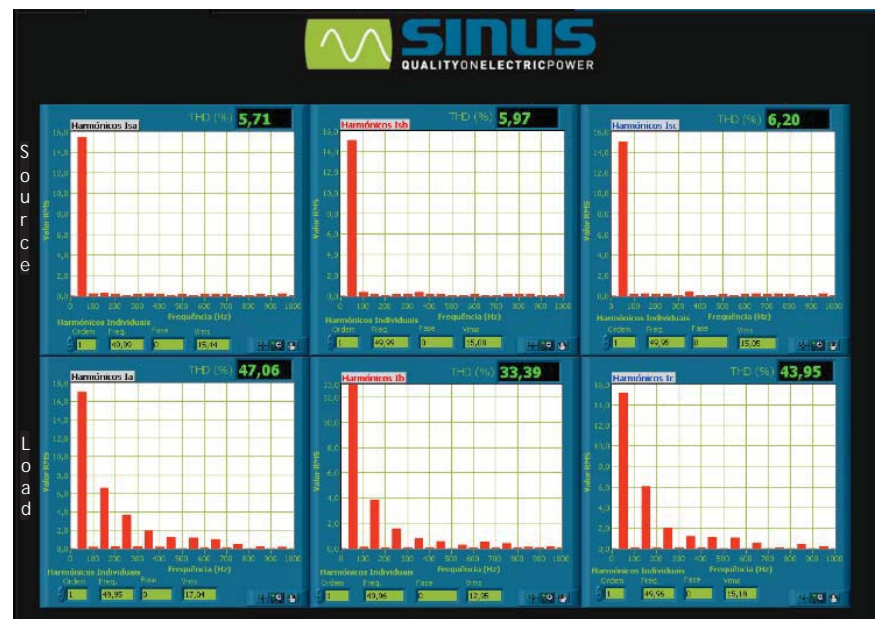

Fig. 7 Current harmonics and $\mathrm{T}$ at load and source sides, registered in installation 2 (Computational Center). 
niversity of inho, where the main loads are computers, desk et and laser printers, lighting, and air-conditioning circuits.

At this electrical installation the load currents present a $\mathrm{T}$ near to 50 , the third harmonic is especially high, although other harmonics are present (Fig. 7). The load presents significant unbalances at certain periods of the day, and the neutral current is high not only due to the unbalance, but specially due to the third order harmonic at the phase currents, resulting in a neutral current with a $150 \mathrm{z}$ fundamental frequency. As a result of the Active Power Filter operation, the three phase currents are enhanced, the waveforms are approximately sinusoidal (Fig. 6), with a T around 6 . At source side the three phase currents become balanced, the neutral current is reduced from $16.5 \mathrm{~A}$ to $1 \mathrm{~A}$, and the total power factor is increased from 0.88 to 0 .

\section{$i$ ica $a$ i ab ra $r$ a pia}

The third demonstration site is the electrical switchboard of the clinical analyses laboratory of a hospital. ere, the loads

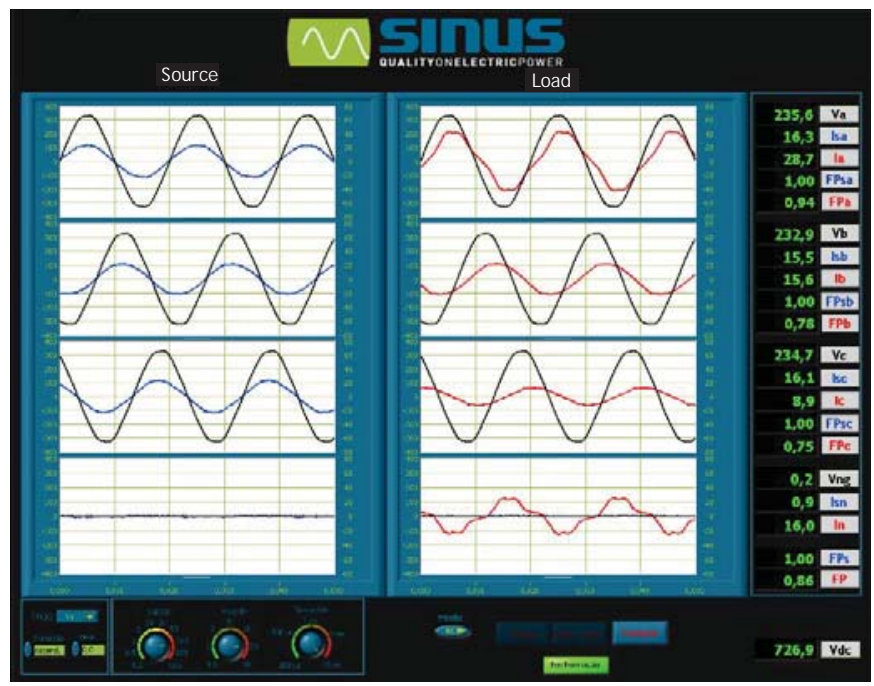

Fig. 8 System voltages and currents waveforms at oad and Source sides, registered in installation 3 (Clinical Analysis aboratory).

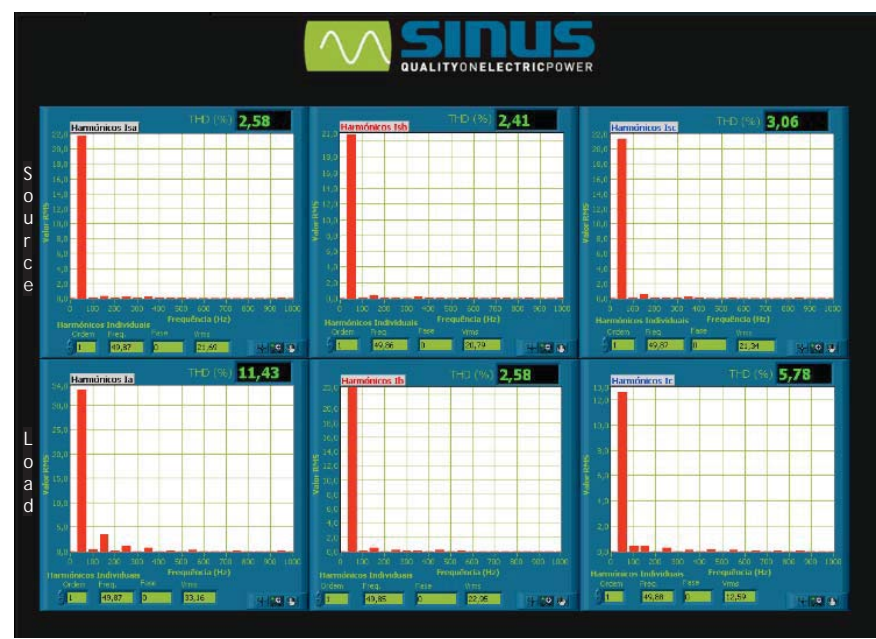

Fig. Current harmonics and $\mathrm{T}$ at oad and Source sides, registered in installation 3 (Clinical Analysis aboratory). are composed by some computers, diverse medical equipments, lighting and air-conditioning circuits. The load currents present low harmonic distortion (the worse case is phase A with a $\mathrm{T}$ near to 11 ), but the unbalance is very significant at certain periods of the day (see Fig. 8 and Fig. ). In Fig. 8 it is possible to see that the phase current is almost $2 \mathrm{~A}$, while the phase current is smaller than A. The phases and also present low power factor (less than 0.78). hen the Shunt Active Power Filter is connected, the current $\mathrm{T}$ at source side decreases in all three phases, reaching values near to 3 , and become balanced with unitary power factor. The neutral current decreases from $16 \mathrm{~A}$ to approximately $1 \mathrm{~A}$.

$$
\text { e ica } r g \text { i rib } i \text { are } e
$$

The fourth demonstration site consists in a medical drugs distribution warehouse. ere, the Active Power Filter was installed at the main switchboard of the warehouse.

The principal loads of this installation are illumination circuits composed by a large number of fluorescent tube

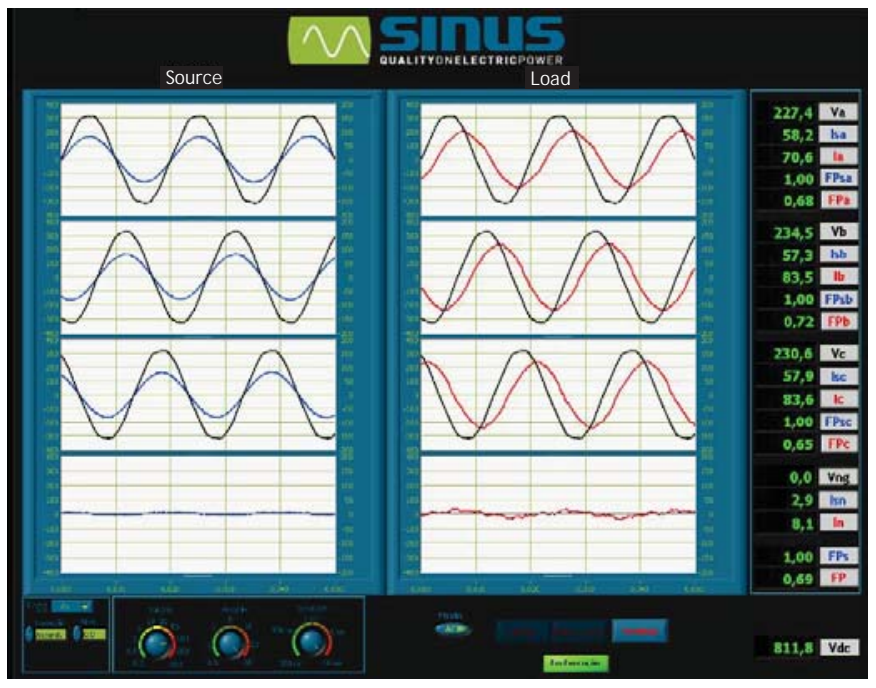

Fig. 10 System voltages and currents waveforms at load and source sides, registered in installation 4 ( edical rugs istribution arehouse).

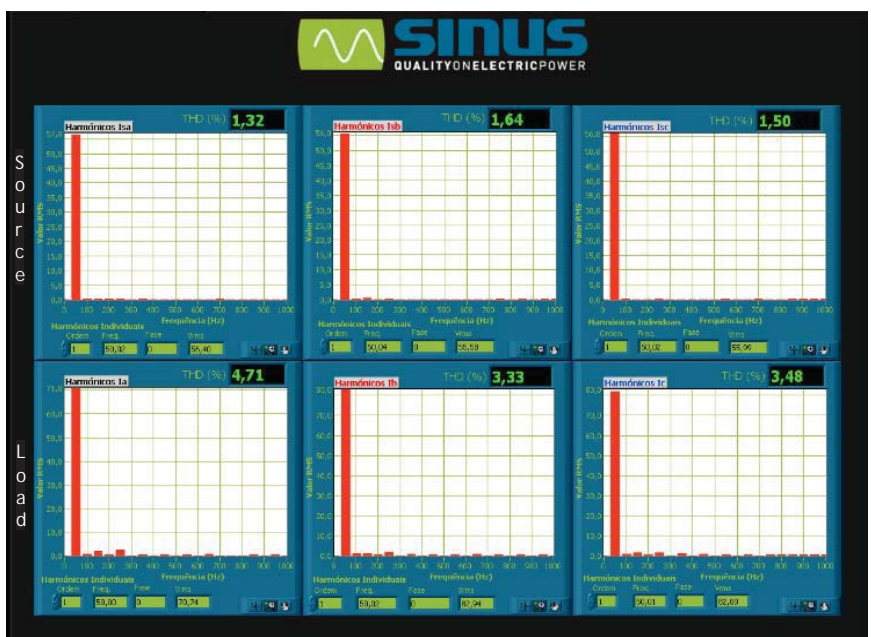

Fig. 11 Current harmonics and $\mathrm{T}$ at oad and Source sides, registered in installation 4 ( edical rugs istribution arehouse). 
lamps, chest refrigerators, some conveyor belt systems, and a central air-conditioning unit.

The load current presents low distortion (the worse case is phase with a T near to 5 ), as it can be seen in Fig. 11. The current unbalance is also small, resulting in a neutral current of around $8 \mathrm{~A}$ (there are not large values of third order harmonics). The major problem at the installation is the power factor. According to Portuguese legislation, if an installation presents a $\tan \varphi$ smaller than 0.4 (equivalent to a displacement power factor smaller than 0.3), then the eactive nergy will be taxed. It is possible to see in Fig. 10 that the total power factor of the installation is lower than 0.7. hen the Shunt Active Power Filter is connected, the current $\mathrm{T}$ at the source side decreases in all three phases, reaching values of less then 2 . The three phase currents become sinusoidal, in phase with the system voltages, and perfectly balanced. The power factor increases from 0.6 to 1 , and the neutral current decreases from $8 \mathrm{~A}$ to 3 A.

\section{Co C SIO S}

This paper presented prototypes of Shunt Active Power Filters, developed at the nergy and Power lectronics aboratory of the niversity of inho, in operation at four different electrical facilities. The presented results confirm the ability of the Active Power Filters to compensate problems like current harmonics, current unbalance and power factor. The developed prototypes presented a good performance in all four demonstration installations.

The next steps in the evolution of the Shunt Active Power Filter development are performing electromagnetic compatibility ( $\mathrm{C}$ ) tests, and realizing some improvements to allow the utilization of these equipments in accordance to the Portuguese and uropean legislation. The presented Active Power Filters are currently in industrialization process by the company FAC C SGPS S.A.

The authors are currently working in nified Power uality Conditioner ( $\mathrm{P}$ C) laboratory prototypes, and researching on multilevel topologies and switching techniques for the inverters of the Active Power Filters, in order to improve the performance of the power stages, by reducing the noise injected in the electric grid and minimizing the operation losses.

$$
\begin{array}{llll}
A C & O & G & T
\end{array}
$$

The authors are grateful to P I (Programa de Incentivos oderniza o da conomia) for funding the Project SI S. The author . G. Pinto is also grateful to FCT for supporting his $\mathrm{Ph}$ scholarship at niversity of inho.

$$
\text { F C S }
$$

[1] A. Bachry . A. Styczynski, An Analysis of istribution System Power uality Problems esulting from oad nbalance and armonics , I P S - Transmission and istribution Conference and xposition, olume 2, 7-12 Sept. 2003 pp. 763766.

[2] o o Afonso, Carlos Couto, lio artins, Active Filters with Control Based on the p-q Theory, I Industrial lectronics Society ewsletter, vol. 47, n 3, Sept. 2000, pp. 5-10.

[3] Gyugi and . C. Strycula, Active AC Power Filters , I -IAS Annual eeting ecord, 1 76, pp. 52 -535.

[4] erdelho, P., arques, G., An Active Power Filter and nbalanced Current Compensator, I Trans. Industrial lectronics, vol. 44, n 3, une 1 7, pp. 321-328.

[5] os Batista, lio S. artins, o o . Afonso, ow-Cost Power uality onitor Based on a PC, ISI 2003 - I International Symposium on Industrial lectronics, io de aneiro, Brazil, -11 une 2003, ISB : 0-7803-7 12-8.

[6] . Akagi, . anazawa, A. abae, Generalized Theory of the Instantaneous eactive Power in Three-Phase Circuits, IP C 83 - Int. Power lectronics Conf., Tokyo, apan, 1 83, pp. 1375-1386.

[7] . Aredes . . atanabe ew Control Algorithms for Series and Shunt Three-Phase Four- ire Active Power Filters I Transactions on Power elivery, vol. 10, no. 3, ul. 15 pp. $164-1656$.

[8] S. Buso . alesani P. attavelli Comparison of Current Control Techniques for Active Filter Applications I Transactions on Industrial lectronics, vol. 45, Issue 5, Oct. 18 pp. 72272.

[ ] Pedro eves, Gabriel Pinto, icardo Pregitzer, u s onteiro, o o. Afonso, xperimental esults of a Single-Phase Shunt Active Filter Prototype with ifferent Switching Techniques, Proceedings of ISI 2007- I International Symposium on Industrial lectronics, 4-7 une 2007, igo, Spain, ISB :1-4244-0755- .

[10] . Pregitzer, .C. Costa, lio S. artins, . . Afonso, Simulation and Implementation esults of a 3 Phase 4 ire Shunt Active Power Filter, C O Proceedings of the IC P 2006 International Conference on armonics and uality of Power, Cascais, Portugal, 1-5 October 2006. 